\title{
Discomfort of seated persons exposed to low frequency lateral and roll oscillation: Effect of backrest height
}

\author{
George F. Beard ${ }^{1}$, BSc, PhD, and Michael J. Griffin, BSc, PhD \\ Human Factors Research Unit \\ Institute of Sound and Vibration Research \\ University of Southampton \\ United Kingdom \\ 1: Now at Transport Research Laboratory (TRL), Crowthorne.
}

Correspondence concerning this article should be addressed to:

Michael J. Griffin,

Human Factors Research Unit,

University of Southampton,

Highfield,

Southampton, SO17 1BJ,

United Kingdom.

Email: m.j.griffin@soton.ac.uk

Running head: Effect of backrest height 


\section{Highlights}

- Backrests affect the discomfort caused by frequencies of vibration less than $1.0 \mathrm{~Hz}$

- Any benefit depends on backrest height and the frequency and direction of vibration

- A high backrest reduces discomfort caused by lower frequencies of lateral and roll

- A high backrest increases discomfort caused by higher frequencies of roll 


\begin{abstract}
Backrests influence the comfort of seated people. With 21 subjects sitting with three backrest heights (no backrest, short backrest, high backrest) discomfort caused by lateral, roll, and fully roll-compensated lateral oscillation was investigated at frequencies between 0.25 and $1.0 \mathrm{~Hz}$. With lateral oscillation, the short backrest reduced discomfort at frequencies less than $0.63 \mathrm{~Hz}$ and the high backrest reduced discomfort at frequencies less than $1.0 \mathrm{~Hz}$. With roll oscillation, the high backrest reduced discomfort at frequencies less than $0.63 \mathrm{~Hz}$, but increased discomfort at $1.0 \mathrm{~Hz}$. With fully roll-compensated lateral oscillation, the short backrest reduced discomfort at $0.4 \mathrm{~Hz}$ and the high backrest reduced discomfort at 0.5 and $0.63 \mathrm{~Hz}$. As predicted by current standards, a backrest can increase discomfort caused by high frequencies of vibration. However, a backrest can reduce discomfort caused by low frequencies, with the benefit depending on the frequency and direction of oscillation and backrest height.
\end{abstract}

Keywords: discomfort, vibration, backrest 


\section{Introduction}

Impressions of comfort when travelling depend on both 'static comfort' and 'dynamic comfort' (Ebe and Griffin, 2000a; 2000b). Some variables influence comfort irrespective of the motion of the environment (e.g., seat ventilation). Other variables only influence comfort in dynamic conditions (e.g., the extent to which vibration is transmitted through a seat; Griffin, 2007).

The motions of the body caused by low frequency acceleration experienced in vehicles (e.g., during acceleration, braking, and cornering) depend on the characteristics of a seat backrest. With lateral oscillation at frequencies less than $3.15 \mathrm{~Hz}$, movements of the head relative to the seat decrease as the height of a backrest increases to $700 \mathrm{~mm}$ (Brett and Griffin, 1991). At frequencies between 0.2 and $16 \mathrm{~Hz}$, the transmission of vibration to the head can be increased by even a short backrest, most notably with fore-andaft oscillation (Paddan and Griffin, 1988, 1994). Backrest inclination can influence the fore-and-aft resonance frequency of a backrest and the transmissibility of the backrest at resonance (Abdul-Jalil and Griffin, 2007). These differences are thought to arise because backrests alter the transmission of vibration to the body and the transmission of vibration through the body, by changing body posture (Paddan and Griffin, 1988, 1994).

Differences in body motion with different backrest conditions may be expected to cause differences in vibration discomfort, and the effects can be expected to depend on both the frequency and the direction of the vibration. With fore-and-aft and lateral oscillation at frequencies between 2.5 and $63 \mathrm{~Hz}$, contact with a backrest was found to increase discomfort relative to sitting with no backrest (Parsons et al., 1982). A backrest and four-point harness reduced discomfort caused by fore-and-aft oscillation at frequencies between 0.25 and $1.25 \mathrm{~Hz}$ (Wyllie and Griffin, 2009), but increased the discomfort caused by lateral, roll, and pitch oscillation at frequencies in the range 0.5 to $1.6 \mathrm{~Hz}$ (Wyllie and Griffin, 2007; 2009). So a backrest with a fourpoint harness, which restrains the head and the upper-body, will reduce vibration discomfort with fore-and-aft oscillation but increase vibration discomfort with lateral, roll, and pitch oscillation. With horizontal oscillation (i.e., fore-and-aft and lateral) and with rotational oscillation (i.e., roll and pitch) at low frequencies, there was greater discomfort around the head, neck and shoulders with a backrest and four-point harness than when sitting without a backrest, suggesting increased forces at these locations (Wyllie and Griffin, 2007; 2009). Lateral oscillation in the range 0.2 to $1.0 \mathrm{~Hz}$ caused less discomfort when sitting with a backrest (without a four-point harness) than when sitting without a backrest (Beard and Griffin, 2013b). This suggests the additional restraint from a four-point harness can affect the vibration discomfort caused by low frequency horizontal and rotational oscillation.

Tilting a vehicle 'into' a turn (a technique known as 'roll-compensation') can reduce the magnitude of the resultant acceleration imposed on passengers (e.g. Förstberg et al., 1998). When sitting with a 550-mm high backrest and exposed to frequencies of oscillation in the range 0.2 to $0.5 \mathrm{~Hz}$, the discomfort caused by fully roll-compensated lateral oscillation was less than the discomfort caused by either the lateral component or the roll component of the oscillation (Beard and Griffin, 2013a). At higher frequencies, discomfort increased as the frequency of oscillation increased, and at $1.0 \mathrm{~Hz}$ there was similar discomfort with only the roll component of the oscillation as there was with fully roll-compensated lateral oscillation. The influence of backrest height on the discomfort caused by such motions has not previously been investigated. 
The inclination of a backrest also affects vibration discomfort. Sitting with a semi-reclined backrest (reclined to $22.5^{\circ}, 45^{\circ}$ or $67.5^{\circ}$ ) during sinusoidal vertical oscillation at frequencies between 2 and $64 \mathrm{~Hz}$ tended to reduce discomfort relative to sitting with an upright backrest (i.e., $90^{\circ}$ ) or lying fully recumbent (i.e., $0^{\circ}$ ) (Paddan et al., 2012). With vertical vibration beneath a seat, as a backrest reclines the proportion of vibration normal to the backrest increases (Basri and Griffin, 2011a) and the proportion of vibration parallel to the backrest decreases (Basri and Griffin, 2011b), and there are changes to the frequency-dependence of vibration discomfort in both directions. Additionally, as a backrest reclines, less weight is supported at the seat pan, and the frequencydependence of discomfort caused by vertical vibration at the seat pan changes (Basri and Griffin, 2012).

British Standard 6841 (1987) and International Standard ISO 2631-1 (1997) suggest the use of frequency weighting $W_{\mathrm{d}}$ (with an axis multiplying factor of 0.5 ) for evaluating lateral vibration of a backrest and frequency weighting $W_{\mathrm{c}}$ (with an axis multiplying factor of 0.8 ) for evaluating fore-and-aft vibration of a backrest. The standard evaluation method implies backrest vibration will always increase discomfort (the weighted components at the seat and the backrest are summed using the root-sums-of-squares). Although this may be correct for some frequencies, it seems that the effects of backrests on vibration discomfort are complex at very low frequencies (i.e., less than $1 \mathrm{~Hz}$ ) and that backrests have effects at frequencies lower than those currently considered in the standards (i.e., less than $0.5 \mathrm{~Hz}$ ).

Evidence suggests two alternative roles of a backrest: it may increase the transmission of vibration to the head and upper body, thereby increasing discomfort, or it may offer additional postural support to the upper body, thereby decreasing discomfort. Previous research has suggested the sitting posture, the backrest height and the backrest angle can affect the transmission of motion to the upper body and head, but the effect of these characteristics on discomfort is not fully understood.

The study described in this paper was designed to determine how backrest height influences the discomfort caused by lateral oscillation, roll oscillation, and fully roll-compensated lateral oscillation at frequencies between 0.25 and $1.0 \mathrm{~Hz}$. Sitting with a backrest was expected to reduce the muscular effort required to maintain an upright posture during lateral oscillation, thereby reducing discomfort (Beard and Griffin, 2013b), with the reduction dependent on the backrest height. However the increased transmission of motion to the upper body and the head with a full-height backrest was expected to increase discomfort during roll oscillation, with any detrimental effects of a backrest most notable at the highest frequencies.

\section{Method}

\subsection{Apparatus}

Motions were produced by a six-axis motion simulator in the Human Factors Research Unit of the Institute of Sound and Vibration Research at the University of Southampton. The simulator was capable of $\pm 0.5 \mathrm{~m}$ vertical motion, $\pm 0.25 \mathrm{~m}$ horizontal motion, and about $\pm 20^{\circ}$ of rotational motion. Subjects sat on a rigid seat positioned so that the centre of the seat surface was at the centre of the motion platform (approximately $2.5 \mathrm{~m}$ by $3.0 \mathrm{~m})$.

The seat consisted of a flat rigid seat pan ( 510 by $400 \mathrm{~mm}$ ) located $480 \mathrm{~mm}$ above the motion platform. The surface of the seat pan was covered in a hard rubber less than $2 \mathrm{~mm}$ in thickness to increase surface friction. 
Subjects sat with one of three backrest configurations: (i) without a backrest, (ii) with a short rigid backrest 295 $\mathrm{mm}$ high by $600 \mathrm{~mm}$ wide), and (iii) with a high rigid backrest ( $650 \mathrm{~mm}$ high by $600 \mathrm{~mm}$ wide). Both backrests were rigid, but contoured in shape so as to provide lateral support to the body (Figure 1). Rigid backrests were used instead of cushioned backrests so that the conditions could be repeated in other studies. At the frequencies of motion examined in this study, the transmissibility of a soft backrest will be the same as the transmissibility of a rigid backrest (i.e. 1.0).

Subjects were asked to maintain comfortable upright postures, with their backs in full contact with any backrest, and their hands on their laps and their feet flat on the floor (i.e., platform of the motion simulator). If necessary, subjects were provided with a footrest to ensure a sitting posture with the thighs parallel to the floor. Subjects wore a loose lap belt for safety.

During motion exposure, subjects wore headphones producing white noise at $65 \mathrm{~dB}(\mathrm{~A})$ in order to mask the sounds of the simulator. The experimenter communicated with subjects through a microphone connected to the headphones by interrupting the white noise.

\section{FIGURE 1 ABOUT HERE}

\subsection{Experimental design}

The experiment adopted a repeated measures (within-subjects) design. Subjects were exposed to a series of motion stimuli whilst seated in one of the three seating conditions (without backrest, with a short backrest, and with a high backrest - see Figure 1) in each of three experimental sessions (conducted on separate days). At the start of each session, subjects were trained on the method of absolute magnitude estimation using a set of practice motions (all three directions of oscillation at the lowest and highest magnitudes - see Section 2.3). Each session consisted of three parts. In part 1 (equivalent comfort contours) subjects used the method of absolute magnitude estimation to rate the discomfort produced by lateral oscillation, roll oscillation, and fully roll-compensated lateral oscillation at frequencies between 0.25 and $1.0 \mathrm{~Hz}$ whilst seated in one of the backrest conditions. In part 2 (relative discomfort) subjects used absolute magnitude estimation to rate discomfort caused by $0.5-\mathrm{Hz}$ lateral oscillation where motions were experienced both without a backrest and with either the short backrest or the high backrest. In part 3 (body map), for every stimulus, the subjects used a labelled diagram of the body (Figure 2) to indicate where they felt discomfort, choosing as many locations as they felt appropriate.

The order of presentation of motion stimuli within each experimental part was fully randomised for each subject. The order of the three experimental sessions was varied for each subject using a Latin square.

\section{FIGURE 2 ABOUT HERE}

\subsection{Motion stimuli}

The motion stimuli consisted of seven frequencies at the preferred one-third octave centre frequencies from 0.25 to $1.0 \mathrm{~Hz}$. Each frequency was presented at, nominally, eight magnitudes in logarithmic series from 0.08 to $0.40 \mathrm{~ms}^{-2}$ r.m.s. (Due to simulator limitations, five magnitudes of lateral oscillation ( 0.08 to $0.20 \mathrm{~ms}^{-2}$ r.m.s.) were presented at $0.25 \mathrm{~Hz}$ and seven magnitudes ( 0.08 to $0.315 \mathrm{~ms}^{-2}$ r.m.s.) at $0.315 \mathrm{~Hz}$. Seven magnitudes 
of roll oscillation (equivalent to 0.08 to $0.315 \mathrm{~ms}^{-2}$ r.m.s.) were presented at $1.0 \mathrm{~Hz}$. Seven magnitudes of rollcompensated oscillation were presented at $0.8 \mathrm{~Hz}\left(0.08\right.$ to $0.315 \mathrm{~ms}^{-2}$ r.m.s.) and six magnitudes (0.08 to 0.25 $\mathrm{ms}^{-2}$ r.m.s.) at $1.0 \mathrm{~Hz}$ ).

For roll oscillation, the magnitude was defined by the acceleration in the plane of the seat (i.e., due to gravity). For roll-compensated lateral oscillation, the lateral oscillation and the roll oscillation were combined in phase such that the resultant acceleration in the plane of the seat was zero. This procedure is illustrated in Figure 2 , which shows the acceleration waveform in the plane of the seat for lateral oscillation, roll oscillation, and rollcompensated lateral oscillation at $0.5 \mathrm{~Hz}$. All motion stimuli were transient waveforms with a 3.5 cycle duration (as shown in Figure 3) generated from the product of a sine wave of the desired frequency and a half-sine of the same duration. The motions were generated within MATLAB (version R2010a research) using the HVLab toolbox (version 1.0).

\section{FIGURE 3 ABOUT HERE}

\subsection{Subjects}

Twenty-one male volunteers aged between 19 and 33 years (median age 25.0 years, inter-quartile range, IQR, 7.0 years; median weight $71.3 \mathrm{~kg}$, IQR 19.0; median stature $1.76 \mathrm{~m}$, IQR $0.08 \mathrm{~m}$ ) participated in the experiment. Subjects were recruited from the staff and student populations of the University of Southampton.

\subsection{Analysis}

The physical magnitudes, $\varphi$, of the motion stimuli were related to the subjective magnitude estimates, $\psi$, using Stevens' power law (Stevens, 1975):

$$
\psi=k \varphi^{n}
$$

The exponent, $n$, (i.e., the rate of growth of discomfort) and the constant, $k$, were determined by performing linear regression on the logarithmic transformation of Equation 1 :

$$
\log _{10} \psi=\log _{10} k+n \log _{10} \varphi
$$

Lateral oscillation of the rigid seat without backrest at a frequency of $0.5 \mathrm{~Hz}$ and a magnitude of $0.2 \mathrm{~ms}^{-2}$ r.m.s. was selected as a 'common reference' for constructing equivalent comfort contours. A 'normalisation' factor was determined in order to normalise the data for all subjects such that the reference condition was assigned a value of 100 . Normalisation factors were calculated using Equation 3 :

$$
\text { Normalisation factor }=\left(100 / \psi_{\text {Reference }}\right)
$$

where $\psi_{\text {Reference }}$ is the subjective magnitude corresponding to the reference condition, obtained through linear regression of Equation 2. Normalisation factors were determined for each subject.

Values for $n$ and $k$ were determined for each individual subject for each frequency and direction of oscillation using normalised magnitude estimates from part 1 (equivalent comfort contours). Equivalent comfort contours for normalised subjective magnitudes, $\psi$, of $50,63,80,100,125,160$, and 200 were calculated for each subject and all three directions of oscillation using Equation 1. 
The data from part 2 (relative discomfort) were used to calculate a 'backrest factor' to adjust the equivalent comfort contours for the seat with a short backrest, and for the seat with a high backrest (obtained in part 1) so that discomfort relative to the seat without backrest could be examined. The backrest factor was calculated using Equation 4:

$$
\text { Backrest factor }=\left(\varphi_{\text {NoBackrest }}\right) /\left(\varphi_{\text {Backrest }}\right)
$$

where $\varphi_{\text {Backrest }}$ is the acceleration magnitude of a $0.5-\mathrm{Hz}$ lateral test motion in part 2 that caused discomfort equivalent to a subjective magnitude of 100 on the seat with either a short or high backrest, and $\varphi_{\text {NoBackrest }}$ is the acceleration magnitude of a $0.5-\mathrm{Hz}$ lateral test motion in part 2 that caused discomfort equivalent to a subjective magnitude of 100 on the seat without backrest. Relative equivalent comfort contours for the short backrest and the high backrest configurations were adjusted by applying the backrest factors to the individual equivalent comfort contours for the short and high backrest constructed from the part 1 data.

The data from part 3 (body map) were used to assess the effect of backrest and the frequency of lateral oscillation, roll oscillation, and fully roll-compensated lateral oscillation on the location of discomfort.

The non-parametric Friedman test was used to investigate the overall effect of frequency of oscillation, direction of oscillation, and backrest height on the rates of growth of discomfort and the equivalent comfort contours. The Wilcoxon matched-pairs signed ranks test was used to examine specific differences in rates of growth of discomfort and equivalent comfort contours between backrest conditions, frequencies, and directions. The McNemar dichotomous test was used to test for significant trends in the body map data. Median rates of growth of discomfort and median equivalent comfort contours were used to identify overall trends in the data. The Bonferroni correction was used where there were multiple comparisons.

\section{Results}

\subsection{Rate of growth of discomfort}

Median rates of growth of discomfort for the three directions of oscillation (lateral, roll, and fully rollcompensated lateral oscillation) with the three seat configurations (no backrest, short backrest, and high backrest) are shown in Figure 4.

\section{Effect of backrest height}

The height of the backrest had no significant effects on the rate of growth of discomfort, except with $0.4-\mathrm{Hz}$ lateral oscillation ( $p=0.023$; Friedman) and 0.8 - and $1.0-\mathrm{Hz}$ roll oscillation ( $p=0.023$ and 0.013 , respectively; Friedman).

\section{Effect of frequency of oscillation}

Rates of growth discomfort varied with the frequency of oscillation for all directions (lateral, roll and fully rollcompensated lateral oscillation) with all three backrest configurations (no backrest, short backrest and high backrest) ( $p<0.003$; Friedman; Figure 3), except for lateral oscillation with no backrest and with the short backrest $(p>0.05$; Friedman) and fully roll-compensated lateral oscillation with the high backrest $(p=0.301$; Friedman). 
For lateral oscillation with the high backrest, the rate of growth of discomfort was negatively correlated with frequency $(R=-0.424, p<0.001$; Spearman). In all backrest conditions with roll oscillation, the rate of growth of discomfort was negatively correlated with frequency $(R<-0.334, p<0.001$; Spearman). With fully rollcompensated lateral oscillation there were no significant correlations between the rate of growth of discomfort and the frequency of oscillation ( $p>0.05$; Spearman).

\section{Effect of direction of oscillation}

Rates of growth of discomfort varied with the direction of oscillation in some conditions: with no backrest at $0.63 \mathrm{~Hz}$ and $1.0 \mathrm{~Hz}$ ( $p=0.013$ and 0.007 , respectively; Friedman); with the short backrest at $0.63 \mathrm{~Hz}$ and 1.0 $\mathrm{Hz}(p=0.023$ and 0.031 , respectively; Friedman), and; with the high backrest at $0.25 \mathrm{~Hz}, 0.8 \mathrm{~Hz}$ and $1.0 \mathrm{~Hz}$ ( $p$ $=0.024,0.012$ and 0.001, respectively; Friedman).

\section{FIGURE 4 ABOUT HERE}

\subsection{Vibration discomfort}

\section{Effect of backrest height}

The height of the backrest influenced the magnitude of vibration required to produce discomfort equivalent to a subjective magnitude of 100 for lateral oscillation (at all frequencies except 0.8 and $1.0 \mathrm{~Hz} ; p<0.031$; Friedman), for roll oscillation (at all frequencies except $0.4,0.63$ and $0.8 \mathrm{~Hz} ; p<0.018$; Friedman) and for fully roll-compensated lateral oscillation (at all frequencies except $0.25,0.63$ and $0.8 \mathrm{~Hz} ; p<0.05$; Friedman) (Figure 5).

\section{FIGURE 5 ABOUT HERE}

During lateral oscillation, the discomfort was greater without backrest than with the short backrest at 0.315 , 0.4 and $0.5 \mathrm{~Hz}(p<0.003$; Wilcoxon) and greater without a backrest than with the high backrest at all frequencies except $1 \mathrm{~Hz}(p<0.011$; Wilcoxon). The discomfort caused by lateral oscillation did not differ significantly between the short backrest and the high backrest ( $p>0.05$; Wilcoxon).

Likewise, roll oscillation caused greater discomfort without a backrest than with the high backrest at frequencies from 0.25 to $0.5 \mathrm{~Hz}(p<0.013$; Wilcoxon), but there was greater discomfort with the high backrest than without a backrest or with the short backrest at $1 \mathrm{~Hz}(p<0.008$; Wilcoxon).

Discomfort caused by fully roll-compensated lateral oscillation was greater without backrest than with the short backrest at $0.4 \mathrm{~Hz}(p=0.003$; Wilcoxon) and greater without a backrest than with the high backrest at 0.5 and $0.63 \mathrm{~Hz}(p<0.011$; Wilcoxon).

No other statistically significant effects of backrest height on equivalent comfort contours were found.

\section{Effect of frequency and direction of oscillation}

The frequency of oscillation influenced the acceleration required to produce a subjective magnitude of 100 with lateral oscillation, roll oscillation, and fully roll-compensated lateral oscillation with all three backrest conditions (Figure 5; $p<0.011$; Friedman). 
The equivalent comfort contours for lateral oscillation show ranges of frequency with approximately constant acceleration ( 0.315 to $0.63 \mathrm{~Hz}$ without a backrest, $0.315 \mathrm{~Hz}$ to $0.5 \mathrm{~Hz}$ with a short backrest, and $0.25 \mathrm{~Hz}$ to 0.4 $\mathrm{Hz}$ with a high backrest). At the higher frequencies, the equivalent comfort contours decline (about $1 \mathrm{~dB}$ per octave from 0.63 to $1.0 \mathrm{~Hz}$ without a backrest, $3 \mathrm{~dB}$ per octave from 0.5 to $1.0 \mathrm{~Hz}$ with a short backrest, and 2 $\mathrm{dB}$ per octave from 0.4 to $1.0 \mathrm{~Hz}$ with a high backrest), indicating increased sensitivity to acceleration with increasing frequency of lateral oscillation.

The equivalent comfort contours for roll oscillation are similar to those for lateral oscillation at low frequencies, but show a much steeper decline at frequencies from 0.4 to $1.0 \mathrm{~Hz}$ (about $6 \mathrm{~dB}$ per octave without a backrest and with a short backrest, and $9 \mathrm{~dB}$ per octave with a high backrest).

The equivalent comfort contours for fully roll-compensated lateral oscillation are similar to those for roll oscillation: constant acceleration at the lowest frequencies ( 0.315 to $0.4 \mathrm{~Hz}$ without a backrest, 0.25 to $0.4 \mathrm{~Hz}$ with a short backrest, and 0.25 to $0.5 \mathrm{~Hz}$ with a high backrest) but declining at higher frequencies (about $7 \mathrm{~dB}$ per octave without a backrest, $6 \mathrm{~dB}$ per octave with a short backrest, and $9 \mathrm{~dB}$ per octave with a high backrest).

At all frequencies, and with all three backrest heights, the acceleration required to produce a subjective magnitude of 100 depended on the direction of oscillation (Figure 6; $p<0.001$, Friedman). The effect of direction of oscillation on discomfort was similar to that reported previously (Beard and Griffin, 2013a).

\section{FIGURE 6 ABOUT HERE}

\section{Effect of magnitude of oscillation}

Equivalent comfort contours were calculated for subjective magnitudes from 50 to 200 (Figure 7). For lateral oscillation with the high backrest, and for roll oscillation with all three backrest conditions, the dispersion between equivalent comfort contours representing subjective magnitudes of 50 and 200 increases with increasing frequency of oscillation from 0.25 to $1.0 \mathrm{~Hz}$. This is consistent with the negative correlation between the rate of growth of discomfort and the frequency of oscillation (as shown in Figure 4). The dispersion of the equivalent comfort contours for fully roll-compensated lateral oscillation increase in the range 0.4 to $0.5 \mathrm{~Hz}$, consistent with reduced rates of growth of discomfort in this range.

\section{FIGURE 7 ABOUT HERE}

\subsection{Location of discomfort}

The incidence of discomfort at the shoulders, upper back, stomach, ischial tuberosities and lower thighs was dependent on the height of the backrest $(p<0.05$; Cochran's $Q)$. Discomfort at the upper back was more frequent with a high backrest than with either no backrest or a short backrest during $0.8-\mathrm{Hz}$ lateral oscillation ( $p=0.008$; McNemar). Discomfort at the ischial tuberosities was more frequent when sitting with no backrest than when sitting with a short backrest during 1.0- $\mathrm{Hz}$ lateral oscillation ( $p=0.008$; McNemar). No other statistically significant effects of backrest on the location of discomfort were found.

The incidence of discomfort at the neck, shoulders, upper back, stomach, ischial tuberosities, lower thighs, and lower legs was found to be dependent on the direction of oscillation ( $p<0.05$; Cochran's Q). However, post-hoc analysis with the Bonferroni correction revealed no statistically significant specific differences in the 
location of discomfort between lateral oscillation, roll oscillation, and fully roll-compensated lateral oscillation at any frequency with any of the three backrests.

\section{Discussion}

\subsection{Rate of growth of discomfort}

Median rates of growth of discomfort varied between 0.6 and 1.6, consistent with those reported previously with similar motions on a rigid seat without backrest and with a 550-mm backrest (Beard and Griffin, 2014; 2013a; Figure 8). The type of backrest had little effect on the rate of growth of discomfort, except with 0.8- and 1.0-Hz roll oscillation where the rate of growth of discomfort was least with the high backrest. Similarly, a fullheight backrest with four-point harness did not influence rate of growth of discomfort reported previously (Wyllie and Griffin, 2007). A low rate of growth of discomfort implies that a unit increase in the physical magnitude of oscillation results in only a slight increase in discomfort. The findings therefore suggest less sensitivity to changes in the magnitude of roll oscillation at 0.8 and $1.0 \mathrm{~Hz}$ when sitting with a high backrest than when sitting with either a short backrest or no backrest.

Median rates of growth of discomfort decreased with increasing frequency of oscillation (Figure 4), except for lateral oscillation without a backrest, with the short backrest, and with fully roll-compensated lateral oscillation with the high backrest. Reductions in the rate of growth with increasing frequency of lateral and roll oscillation have been reported previously for a rigid seat with a full-height backrest (Beard and Griffin, 2013a), a rigid seat with full-height backrest and four-point harness (Wyllie and Griffin, 2007), a rigid seat without backrest (Wyllie and Griffin, 2007; Beard and Griffin, 2014), and a foam seat without backrest (Beard and Griffin, 2014). A decreasing rate of growth of discomfort with increasing frequency implies that a given percentage increase in motion magnitude causes a greater increase in discomfort at low frequencies than at high frequencies. As a result, the dispersion of equivalent comfort contours for subjective magnitudes between 50 and 200 increased with increasing frequency of oscillation, as shown in Figure 7.

\section{FIGURE 8 ABOUT HERE}

\subsection{Effects of backrest on vibration discomfort}

During lateral oscillation at frequencies less than $0.63 \mathrm{~Hz}$, there was less discomfort when sitting with a short backrest than sitting without a backrest. The 295-mm short backrest provided support for the lumbar region of the back, which may have reduced the muscular effort required to maintain an upright sitting posture during lateral oscillation. The thoracic region of the back was not supported by the short backrest, so subjects either allowed their upper-body to sway with the motion or used muscle activity to retain an upright posture. During lateral oscillation at all frequencies less than $1 \mathrm{~Hz}$, there was less discomfort sitting with a high backrest than sitting without a backrest. The addition of lateral support to the thoracic region of the back with a high backrest may have reduced upper-body sway, so the reduced discomfort may have been associated with reduced muscular activity required to maintain an upright posture.

Although the median equivalent comfort contours suggest the short backrest reduced discomfort caused by roll oscillation, no statistically significant effects were found. Compared to sitting with no backrest, or with the short backrest, the high backrest reduced discomfort at frequencies from 0.25 to $0.5 \mathrm{~Hz}$ but increased 
discomfort at $1.0 \mathrm{~Hz}$. At the lower frequencies, the lateral support offered by the high backrest may have reduced the muscle activity required to maintain an upright posture during roll oscillation. If the lateral acceleration in the plane of the seat due to roll displacement through the gravity vector is constant, then the lateral acceleration of the backrest produced by roll oscillation increases with increasing height above the centre-of-rotation (the seat surface) and with increasing frequency of oscillation. Therefore, with $1-\mathrm{Hz}$ roll oscillation there was a greater magnitude of lateral acceleration at the top of the backrest than with lower frequencies of roll oscillation. Increased transmission of lateral acceleration to the upper body and the head with the full-height backrest may account for the increased discomfort (Paddan and Griffin, 1988, 1994; Brett and Griffin, 1991).

Similar to the current study, the discomfort caused by lateral oscillation at frequencies between $0.2 \mathrm{and} 1.0 \mathrm{~Hz}$ was less with a full-height backrest than without a backrest for both a rigid seat and a cushioned seat (Beard and Griffin, 2014). However, a full-height backrest and a four-point harness increased discomfort during lateral oscillation at frequencies from 0.4 to $1.6 \mathrm{~Hz}$, and during roll oscillation at frequencies from 0.63 to $1.6 \mathrm{~Hz}$ (Wyllie and Griffin, 2007). In that study, subjects were securely fastened to the seat with a four-point harness and unable to move their upper-back or shoulders relative to the backrest, so increased transmission of lateral and roll oscillation to the upper-body and head may have increased discomfort. Restraining subjects with the harness may have extended the detrimental effects of a high backrest seen with $1-\mathrm{Hz}$ roll oscillation in the current study to lower frequencies (i.e., down to $0.63 \mathrm{~Hz}$ ).

The effects of a backrest on discomfort during fore-and-aft oscillation appear to differ from the effects of a backrest on discomfort during lateral oscillation. Compared to sitting with no backrest, sitting with a backrest and four-point harness increased discomfort caused by lateral oscillation at frequencies from 0.315 to $1.6 \mathrm{~Hz}$ (Wyllie and Griffin, 2007) but reduced discomfort caused by fore-and-aft vibration at frequencies between 0.25 and $1.25 \mathrm{~Hz}$ (Wyllie and Griffin, 2009). This might be explained by the high backrest increasing motion in the shoulders and therefore the forces in the neck that control the posture of the unsupported head. The forces are easily accommodated by head nodding in the sagittal plane but require unnatural muscle activity likely to induce discomfort and fatigue in the coronal plane. The seating conditions investigated by Wyllie and Griffin may represent extremes of support but not necessarily extremes of vibration discomfort. The current study with lateral and roll oscillation had 'intermediate' levels of support to the upper body and found effects different from those with a full-height backrest restrained by a four-point harness. The effects of backrest height on discomfort while exposed to fore-and-aft oscillation, pitch oscillation, or pitch-compensated fore-and-aft oscillation, have yet to be explored.

\subsection{Equivalent comfort contours}

Equivalent comfort contours were highly dependent on the frequency of oscillation. When sitting without a backrest, equivalent comfort contours for lateral oscillation required approximately constant acceleration at frequencies from 0.315 to $0.63 \mathrm{~Hz}$, then declined by about $1 \mathrm{~dB}$ per octave from 0.63 to $1.0 \mathrm{~Hz}$. Contours for roll oscillation and fully-roll compensated lateral oscillation were approximately constant between 0.315 and $0.4 \mathrm{~Hz}$ then declined by $6 \mathrm{~dB}$ and $7 \mathrm{~dB}$ per octave, respectively, from 0.4 to $1.0 \mathrm{~Hz}$. Similar findings for a rigid seat without backrest have been reported previously (Wyllie and Griffin, 2007; Beard and Griffin, 2014). Previous equivalent comfort contours for a rigid seat without backrest at these frequencies, and at frequencies 
greater than this range, suggest increasing sensitivity to lateral acceleration with increasing frequency up to about $2 \mathrm{~Hz}$ and then decreasing sensitivity at greater frequencies (Griffin et al., 1982; Morioka and Griffin, 2006).

When sitting with either a short backrest $(295 \mathrm{~mm})$ or a high backrest $(650 \mathrm{~mm})$, the frequency-dependence of equivalent comfort contours for lateral oscillation was roughly similar, remaining constant between 0.25 and $0.5 \mathrm{~Hz}$ and declining by approximately $3 \mathrm{~dB}$ per octave at higher frequencies. However, during roll oscillation and fully roll-compensated lateral oscillation the frequency-dependence of equivalent comfort contours was dependent on the height of the backrest. When expressed in terms of acceleration in the plane of the seat (in $\mathrm{ms}^{-2}$ r.m.s.), the contours have approximately constant acceleration between 0.25 and $0.4 \mathrm{~Hz}$ with both backrests, but decline from 0.4 to $1.0 \mathrm{~Hz}$ at approximately $6 \mathrm{~dB}$ per octave with the short backrest and at approximately $9 \mathrm{~dB}$ per octave with the high backrest. Previous equivalent comfort contours for roll oscillation (expressed in rotational acceleration: rads $^{-2}$ r.m.s.) on a rigid seat with a 550-mm high backrest (Beard and Griffin, 2013a) and a rigid seat with a 570-mm high backrest and four-point harness (Wyllie and Griffin, 2007) are compared with those from the current study in Figure 9. With the 295-mm high backrest and with no backrest, the roll acceleration required to cause a given degree of discomfort increases with increasing frequency from 0.2 to $1.0 \mathrm{~Hz}$. With the taller backrests, the level of equivalent comfort contours remains approximately constant at frequencies between about 0.5 and $1.0 \mathrm{~Hz}$, suggesting sensitivity is proportional to roll acceleration in this range. The frequency-dependence of equivalent comfort contours is consistent with high backrests increasing the discomfort caused by roll oscillation, especially at higher frequencies.

\subsection{Effects of roll compensation}

Using a rigid seat with a 550-mm high backrest, a rigid seat without a backrest, and a foam seat without a backrest, full roll-compensation of lateral acceleration reduced discomfort at frequencies less than about 0.5 $\mathrm{Hz}$, but increased discomfort at higher frequencies (Beard and Griffin, 2013a; 2014). Similar findings were seen in the current study when using a rigid seat with no backrest, a 295-mm high backrest, and a 650-mm high backrest. This implies that the physical discomfort associated with traversing curves at high-speed (e.g., in tilting trains) can be reduced by appropriate roll-compensation techniques if the motions occur at frequencies less than about $0.5 \mathrm{~Hz}$. With the fully roll-compensated motions used in this study the lateral acceleration was equal and opposite to the acceleration in the plane of the seat caused by roll through the gravitational vector (i.e. 100\% compensation). The effects of other percentage compensations on vibration discomfort, and the interactive effects of backrest height, have not been investigated.

In the range of frequencies investigated in this study, 100\% compensation causes nausea in some passengers (e.g., Ueno et al., 1986; Förstberg et al., 1998; Donohew and Griffin, 2009) and symptoms of motion sickness caused by frequencies less than $0.5 \mathrm{~Hz}$ are reduced when the percentage compensation is reduced to less than $100 \%$ (Donohew and Griffin, 2010). The present study has shown that at frequencies greater than about $0.5 \mathrm{~Hz}, 100 \%$ compensation can worsen the physical comfort of passengers, so it may be concluded that $100 \%$ compensation is not optimum at frequencies less than $0.5 \mathrm{~Hz}$ (because it increases motion sickness) and not optimum at frequencies greater than $0.5 \mathrm{~Hz}$ (because it increases physical discomfort). 


\section{FIGURE 9 ABOUT HERE}

\subsection{The location of discomfort}

At the higher frequencies tested, discomfort during lateral oscillation tended to be more frequently localised at the upper-back when sitting with a high backrest than when sitting with no backrest or with a short backrest. This is consistent with a high backrest increasing the transmission of lateral acceleration to the upper-body (Paddan and Griffin, 1988; Brett and Griffin, 1991). Greater discomfort has also been reported at the head, neck or shoulders when seated with a full-height backrest and four-point harness and it was suggested that the "backrest prevented the torso moving so as to reduce the acceleration reaching the head and neck" (Wyllie and Griffin, 2007, p. 2651). Despite a greater incidence of discomfort at the upper-back with the high backrest than without a backrest, the overall level of discomfort reported during lateral oscillation when sitting with a high backrest was less than when sitting with no backrest (Figure 5). This suggests that an increased incidence of discomfort at the upper-back when sitting with a high backrest was associated with a reduction in the incidence of discomfort at other locations of the body.

Also with high frequencies of lateral oscillation, the discomfort at the ischial tuberosities tended to be greater when sitting with no backrest, consistent with previous findings (Beard and Griffin, 2013b; 2014). Sitting upright without a backrest requires the pelvis to be rolled forward. The pressure on the ischial tuberosities in this posture may be reduced by leaning back against a backrest (e.g., Vos et al., 2006; Kyung and Nussbaum, 2008). Discomfort while exposed to lateral oscillation may result from the downward forces that occur alternately at each ischial tuberosity. Full roll-compensation of lateral oscillation, which balances the lateral forces at the seat surface, reduces discomfort at the ischial tuberosities (Beard and Griffin, 2013a; 2014).

\subsection{Implications for vibration standards}

Current vibration standards suggest that, at all frequencies of oscillation from 0.5 to $80 \mathrm{~Hz}$, discomfort from lateral acceleration at a backrest and discomfort from lateral acceleration at a seat surface may be predicted using the same frequency-weighting (i.e., $W_{\mathrm{d}}$ ) but with lateral vibration at the backrest given half the weight of lateral vibration at the seat (BS 6841, 1987; ISO 2631-1, 1997). Using the root-sums-of-squares method to sum the weighted lateral accelerations at the seat and the back implies that the presence of vibration at the backrest will always increase discomfort. However, the current findings indicate that the discomfort caused by lateral acceleration may be reduced by a short backrest (at frequencies less than $0.63 \mathrm{~Hz}$ ) and by a high backrest (at frequencies less than $1 \mathrm{~Hz}$ ). A similar beneficial effect of a backrest was found for lateral acceleration caused by the gravitational component of roll at frequencies less than $0.63 \mathrm{~Hz}$. At these very low frequencies, the increase in discomfort predicted by the standards is therefore incorrect.

For frequencies greater than $1 \mathrm{~Hz}$, where backrest vibration increases discomfort (e.g., Parsons et al., 1982), it seems appropriate to predict discomfort using the root-sums-of-squares of the weighted acceleration at the seat pan and the backrest. At frequencies less than $1 \mathrm{~Hz}$, a suitably weighted measure of backrest vibration would need to be subtracted from the weighted seat pan acceleration, in order to represent the beneficial effect of a backrest on discomfort as identified in this study. This could provide an algorithm for calculating the beneficial effect of a backrest, but would only be applicable for predicting discomfort at low frequencies (e.g. less than $0.8 \mathrm{~Hz}$ ). Furthermore, the quantification of an appropriate weighting must consider some factors 
whose effects are not yet established (e.g., backrest shape) in addition to the effects of the frequency and direction of oscillation and the height of the backrest.

Although current standards are not intended for predicting the discomfort caused by oscillation at frequencies less than $0.5 \mathrm{~Hz}$, the present results can be used to assess the applicability of weighting $W_{\mathrm{d}}$ (for lateral acceleration) and $W_{\mathrm{e}}$ (for roll acceleration) at frequencies in the range 0.2 to $0.5 \mathrm{~Hz}$. Figure 10 compares these frequency weightings with the reciprocals of the median equivalent comfort contours for lateral, roll and fully roll-compensated lateral oscillation with each backrest height. The equivalent comfort contours have been normalised to unity at $1 \mathrm{~Hz}$ and are shown for seven subjective magnitudes.

\section{FIGURE 10 ABOUT HERE}

For all three seating conditions (i.e., no backrest, short backrest, and high backrest), frequency weighting $W_{\mathrm{d}}$ appears to offer a reasonable approximation to the equivalent comfort contours for lateral oscillation at frequencies from 0.315 to $1.0 \mathrm{~Hz}$, regardless of the sensation magnitude. However, at frequencies less than $0.315 \mathrm{~Hz}, W_{\mathrm{d}}$ appears to underestimate the discomfort caused by lateral oscillation, particularly with high magnitudes when sitting with a high backrest.

Equivalent comfort contours for pure roll acceleration depend on the magnitude of oscillation, so no single frequency weighting is able to provide a good prediction of the discomfort caused by roll at all frequencies less than $1 \mathrm{~Hz}$. Figure 10 shows how the equivalent comfort contours for roll acceleration (rads ${ }^{-2}$ r.m.s.) depend on the sensation magnitude, and this magnitude-dependence varies with the height of a backrest. Frequency weighting $W_{\mathrm{e}}$ has approximately constant gain between 0.5 and $1.0 \mathrm{~Hz}$, suggesting that the discomfort caused by pure roll acceleration (without a backrest) is independent of the frequency of oscillation in this range. The frequency-dependence of discomfort observed in this study suggests a different pattern, with sensitivity to roll acceleration increasing with decreasing frequency from 1.0 to $0.25 \mathrm{~Hz}$.

With fully roll-compensated lateral oscillation, the lateral acceleration in the plane of the seat at the seat surface (i.e., at the centre-of-rotation) is zero, so the frequency-weighting for lateral acceleration is irrelevant. Instead, any weighting for fully roll-compensated lateral oscillation must factor in the roll component of the motion. For all three backrest conditions, when expressed in terms of rotational acceleration (rads ${ }^{-2}$ r.m.s.), the equivalent comfort contours for fully roll-compensated lateral oscillation are roughly constant roll acceleration at frequencies between 0.5 and $0.8 \mathrm{~Hz}$, implying the discomfort caused by roll acceleration is independent of frequency in this range. At frequencies greater than $0.8 \mathrm{~Hz}$ and less than $0.5 \mathrm{~Hz}$, the contours suggest increasing discomfort with decreasing frequency of rotational acceleration. Despite a general underestimation of discomfort, the shape of frequency weighting $W_{\mathrm{e}}$ appears to roughly approximate the frequency-dependence of discomfort caused by fully-roll compensated lateral oscillation at frequencies greater than $0.5 \mathrm{~Hz}$ if discomfort is predicted from the roll component alone.

This research has implications for the methods of predicting discomfort defined in current standards (BS 6841, 1987; ISO 2631-1, 1997). The frequency weighting for lateral oscillation, $W_{\mathrm{d}}$, may offer reasonable predictions of the discomfort caused by frequencies between 0.315 and $1.0 \mathrm{~Hz}$, but will tend to underestimate the discomfort caused by frequencies less than $0.315 \mathrm{~Hz}$. The frequency weighting for roll oscillation, $W_{\mathrm{e}}$, tends to underestimate the discomfort caused by pure roll acceleration at frequencies less than $1.0 \mathrm{~Hz}$. Frequency 
weighting, $W_{\mathrm{e}}$, also underestimates the discomfort caused by fully roll-compensated lateral oscillation, although the frequency-dependence of $W_{\mathrm{e}}$ approximates the frequency-dependence of discomfort caused by fully-roll compensated lateral oscillation at frequencies between 0.5 and $1 \mathrm{~Hz}$ if discomfort is predicted from the roll component alone.

\section{Conclusion}

A backrest can reduce vibration discomfort caused by lateral oscillation at frequencies less than $1.0 \mathrm{~Hz}$, by roll oscillation at frequencies less than $0.63 \mathrm{~Hz}$, and by fully roll-compensated lateral oscillation at frequencies from 0.4 to $0.63 \mathrm{~Hz}$. The discomfort caused by low frequency lateral oscillation is localised at the ischial tuberosities when there is no backrest, but localised in the upper back when sitting with a full-height backrest. Current standards imply that a backrest will always increase vibration discomfort; whilst this is the case with higher frequencies of vibration, a backrest can reduce discomfort with low frequencies of oscillation of the type studied here. The standardised frequency weighting for lateral oscillation, $W_{\mathrm{d}}$, underestimates the discomfort caused by frequencies less than $0.315 \mathrm{~Hz}$, but is reasonable for frequencies from 0.315 to $1.0 \mathrm{~Hz}$. The standard frequency weighting for roll oscillation, $W_{\mathrm{e}}$, is not optimum for predicting the discomfort caused by pure roll oscillation but may contribute to useful predictions of the discomfort caused by fully-roll compensated lateral oscillation at frequencies less than $1.0 \mathrm{~Hz}$. The appropriate frequency weighting for these low frequencies of oscillation depends on the height of any backrest. 


\section{References}

Abdul-Jalii, N.A. and Griffin, M.J. (2007). Fore-and-aft transmissibility of backrests: effect of backrest inclination, seat-pan inclination, and measurement location. Journal of Sound and Vibration, 299, 99-108.

Basri, B. and Griffin, M.J. (2011a). The vibration of inclined backrests: perception and discomfort of vibration applied normal to the back in the x-axis of the body. Journal of Sound and Vibration, 330, 4646-4659.

Basri, B. and Griffin, M.J. (2011b). The vibration of inclined backrests: perception and discomfort of vibration applied parallel to the back in the z-axis of the body. Ergonomics, 54:12, 1214-1227.

Basri, B. and Griffin, M.J. (2012). Equivalent comfort contours for vertical seat vibration: effect of vibration magnitude and backrest inclination. Ergonomics, 55:8, 909-922.

Beard, G.F. and Griffin, M.J. (2013a). Discomfort caused by low frequency lateral oscillation, roll oscillation, and fully roll-compensated lateral oscillation. Ergonomics. 56 (1), 103-114.

Beard, G.F. and Griffin, M.J. (2013b). Discomfort during lateral acceleration: Influence of seat cushion and backrest. Applied Ergonomics, 44 (4), 588-594.Beard, G.F. and Griffin, M.J. (2014). Discomfort of seated persons exposed to lateral and roll oscillation: Effect of seat cushion. Applied Ergonomics, 45(6), 1547-57.

Beard, G.F. and Griffin, M.J. (2014). Discomfort of seated persons exposed to low frequency lateral and roll oscillation: Effect of seat cushion. Applied Ergonomics, 45, 1547-1557.

Brett, M.W. and Griffin, M.J. (1991). Effect of height of backrest support on head motion during exposure to low frequency lateral vibration. In, Proceedings of the Ergonomics Society's 1991 Annual Conference, Southampton, England, 16-19 April 1991.

British Standards Institution, 1987. Measurement and evaluation of human exposure to whole-body mechanical vibration and repeated shock. BS 6841. British Standards Institution, London.

Donohew, B.E. and Griffin, M.J. (2009). Motion sickness with fully roll-compensated lateral oscillation: Effect of oscillation frequency. Aviation, Space and Environmental Medicine, 80, 94-101.

Donohew, B.E. and Griffin, M.J. (2010). Motion sickness with combined lateral and roll oscillation: Effect of percentage compensation. Aviation, Space and Environmental Medicine, 81, 22-29.

Ebe, K. and Griffin, M.J. (2000a). Qualitative models of seat discomfort including static and dynamic factors. Ergonomics, 43 (6), 771-790.

Ebe, K. and Griffin, M.J. (2000b). Quantitative prediction of overall seat discomfort. Ergonomics, 43 (6), 791 806.

Förstberg, J., Andersson, E. and Ledin, T. (1998). Influence of different conditions for tilt compensation on symptoms of motion sickness in tilting trains. Brain Research Bulletin, 47 (5), 525-535.

Griffin, M.J. (2007). Discomfort from feeling vehicle vibration. Vehicle System Dynamics, 45 (7), 679-698.

Griffin, M.J., Whitham, E.M. and Parsons, K.C. (1982). Vibration and comfort I. Translational seat vibration, Ergonomics, 25 (8), 603-630. 
International Organization for Standardization. (1997). Mechanical vibration and shock - evaluation of human exposure to whole-body vibration - Part 1: General requirements. International Standard, ISO 2631-1.

Kyung, G. and Nussbaum, M.A. (2008). Driver sitting comfort and discomfort (part II): Relationships with and prediction from interface pressure. International Journal of Industrial Ergonomics, 38, 526-538.

Morioka, M. and Griffin, M.J. (2006). Magnitude-dependence of equivalent comfort contours for fore-and-aft, lateral and vertical whole-body vibration. Journal of Sound and Vibration, 298, 755-772.

Paddan, G.S. and Griffin, M.J. (1988). The transmission of translational seat vibration to the head - II. Horizontal seat vibration. Journal of Biomechanics, 21 (3), 199-206.

Paddan, G.S. and Griffin, M.J. (1994). Transmission of roll and pitch seat vibration to the head. Ergonomics, 37, 1513-1531.

Paddan, G.S., Mansfield, N.J., Arrowsmith, C.I., Rimell, A.N., King, S.K. and Holmes, S.R. (2012). The influence of seat backrest angle on perceived discomfort during exposure to vertical whole-body vibration. Ergonomics, 55(8), 923-936.

Parsons, K.C., Griffin, M.J. and Whitham, E.M. (1982). Vibration and comfort. III. Translational vibration of the feet and back. Ergonomics, 25, (8), 705-719.

Stevens, S.S., 1975. Psychophysics: introduction to its perceptual, neural, and social prospects. Transaction Publishers, Oxford.

Ueno, M., Ogawa, T., Nakagiri, S., Arisawa, T., Mino, Y., Oyama, K., Kodera, R., Taniguchi, T., Kanazawa, S., Ohta, T., and Aoyama, H. (1986). Studies on motion sickness caused by high curve speed railway vehicles. Japanese Journal of Industrial Health, 28 (4), 266-274.

Vos, G.A., Congleton, J.J., Moore, J.S., Amendola, A.A. and Ringer, L. (2006). Postural versus chair design impacts upon interface pressure. Applied Ergonomics, 37 (6). 619-628.

Wyllie, I.H. and Griffin, M.J. (2007). Discomfort from sinusoidal oscillation in the roll and lateral axes at frequencies between 0.2 and $1.6 \mathrm{~Hz}$. Journal of the Acoustical Society of America, 121, (5), 2644-2654.

Wyllie, I.H. and Griffin, M.J. (2009). Discomfort from sinusoidal oscillation in the pitch and fore-and-aft axes at frequencies between 0.2 and $1.6 \mathrm{~Hz}$. Journal of Sound and Vibration, 324, 453467. 


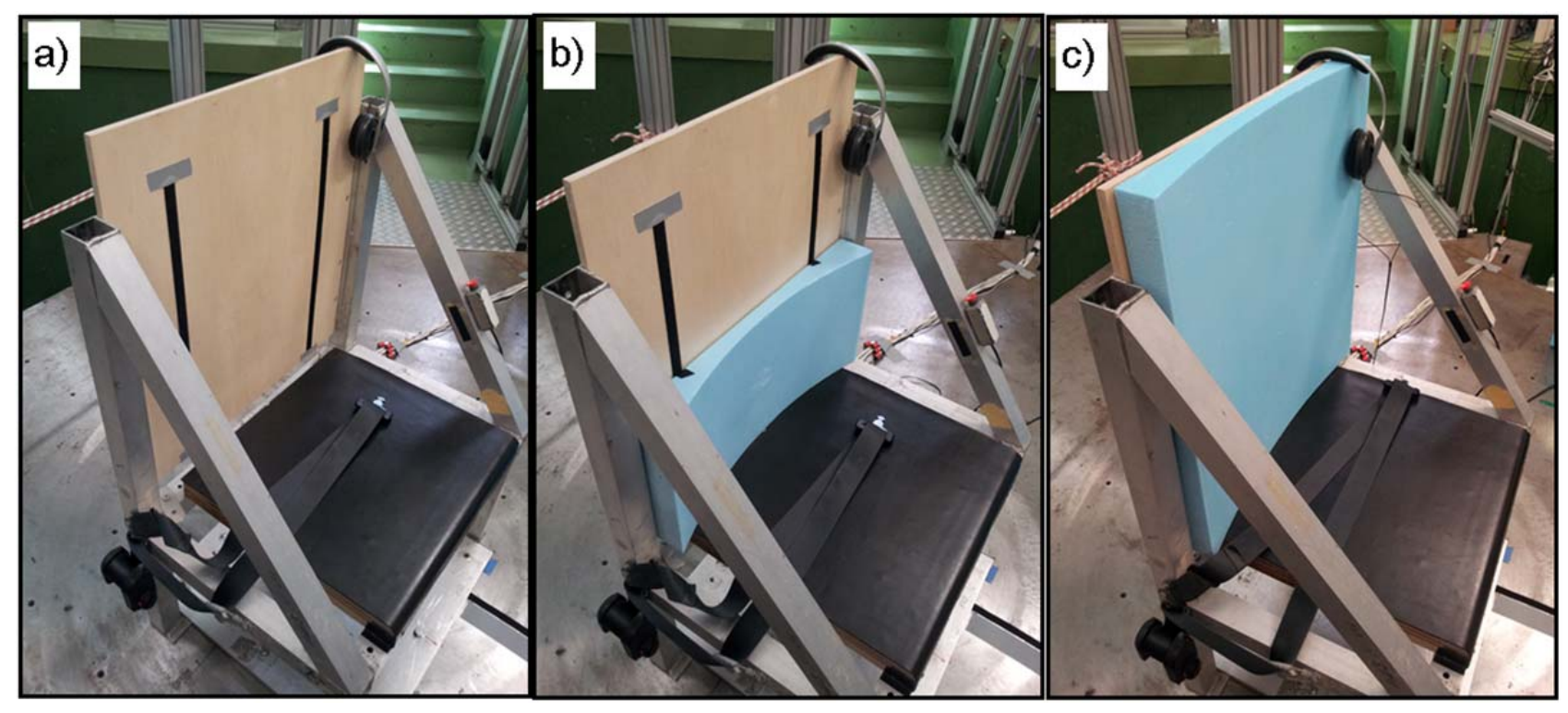

Figure 1 The three backrest conditions: (a) no backrest; (b) short backrest; (c) high backrest. 


\section{BODY MAP}

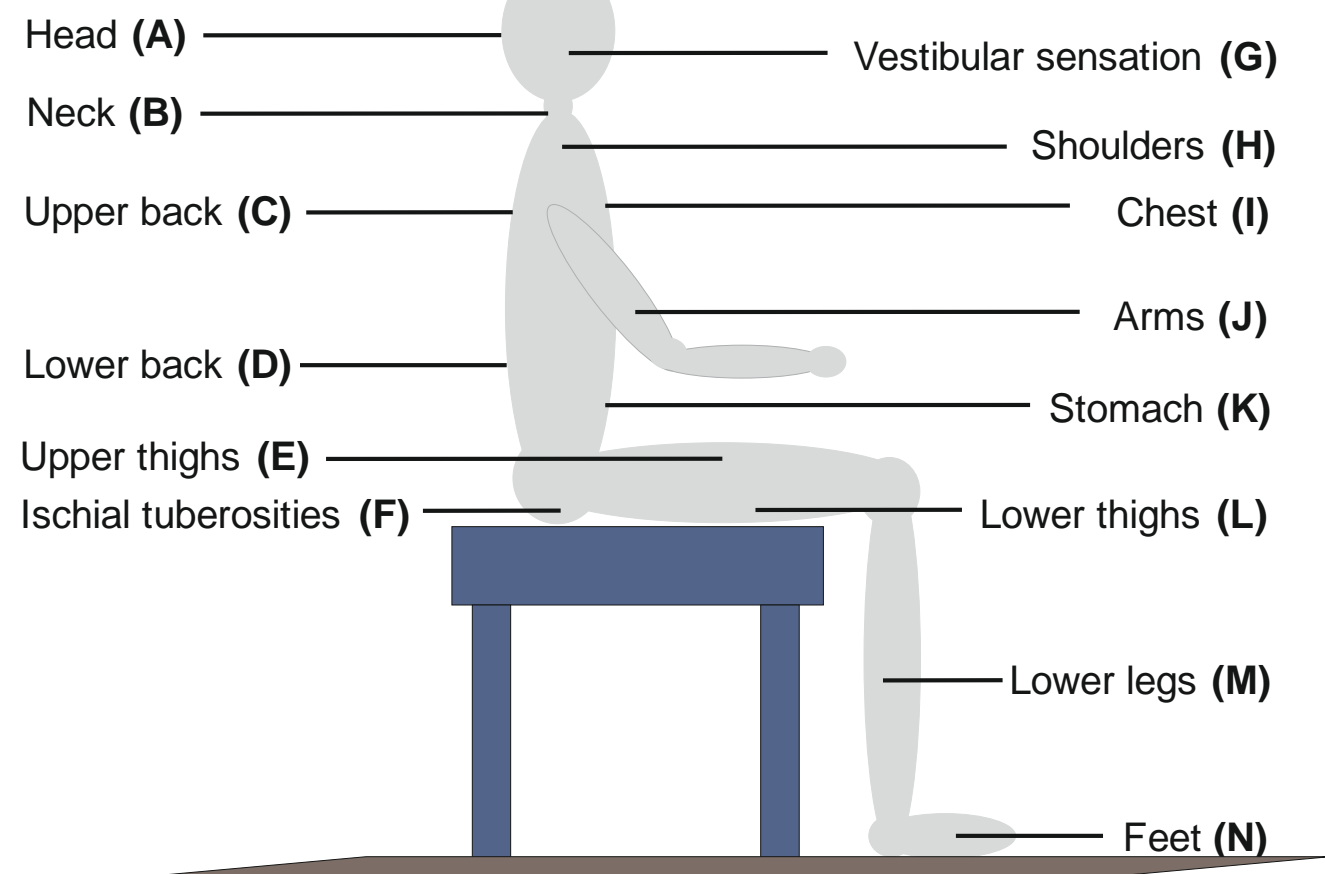

Figure 2 Body map used by subjects to indicate the location of discomfort caused by lateral oscillation, roll oscillation, and fully roll-compensated lateral oscillation. 


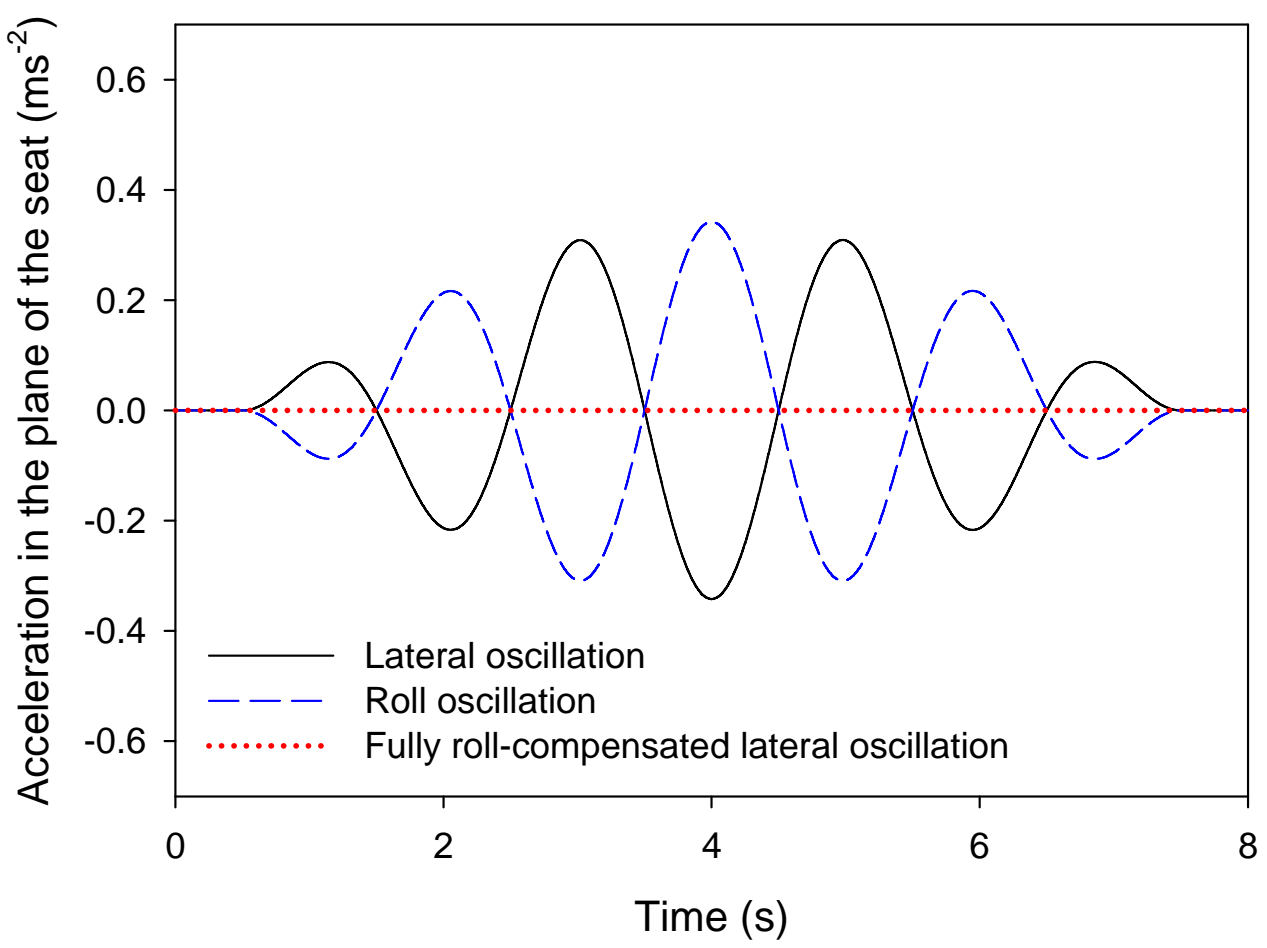

Figure 3 Example waveforms for $0.5-\mathrm{Hz}$ oscillation showing the acceleration in the plane of the seat for lateral oscillation, roll oscillation, and fully roll-compensated lateral oscillation. 


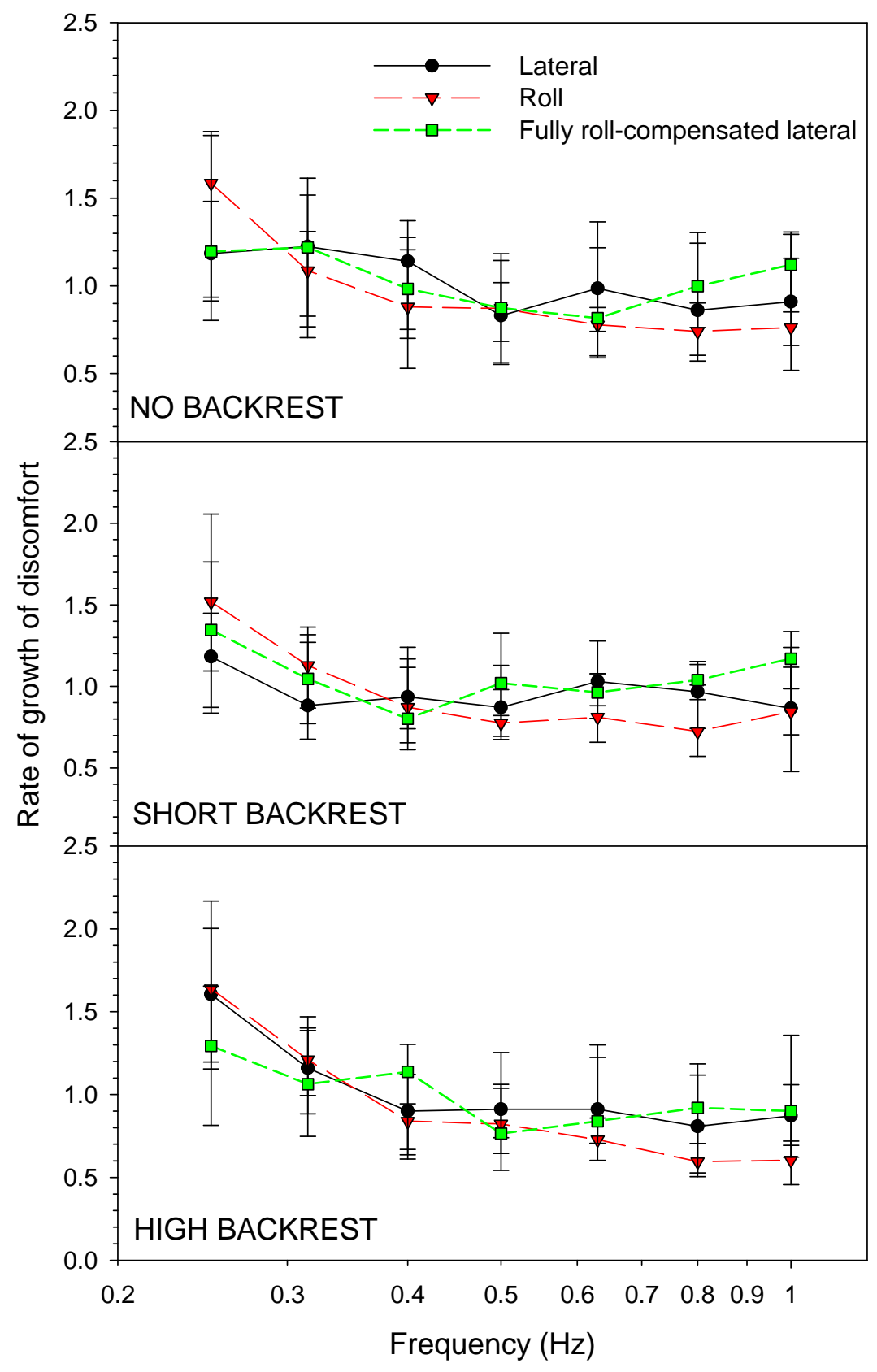

Figure 4 Median rates of growth of discomfort for lateral oscillation, roll oscillation, and fully roll-compensated lateral oscillation with no backrest, a short backrest and a high backrest. Upper and lower error bars show $75^{\text {th }}$ and $25^{\text {th }}$ percentiles, respectively. 


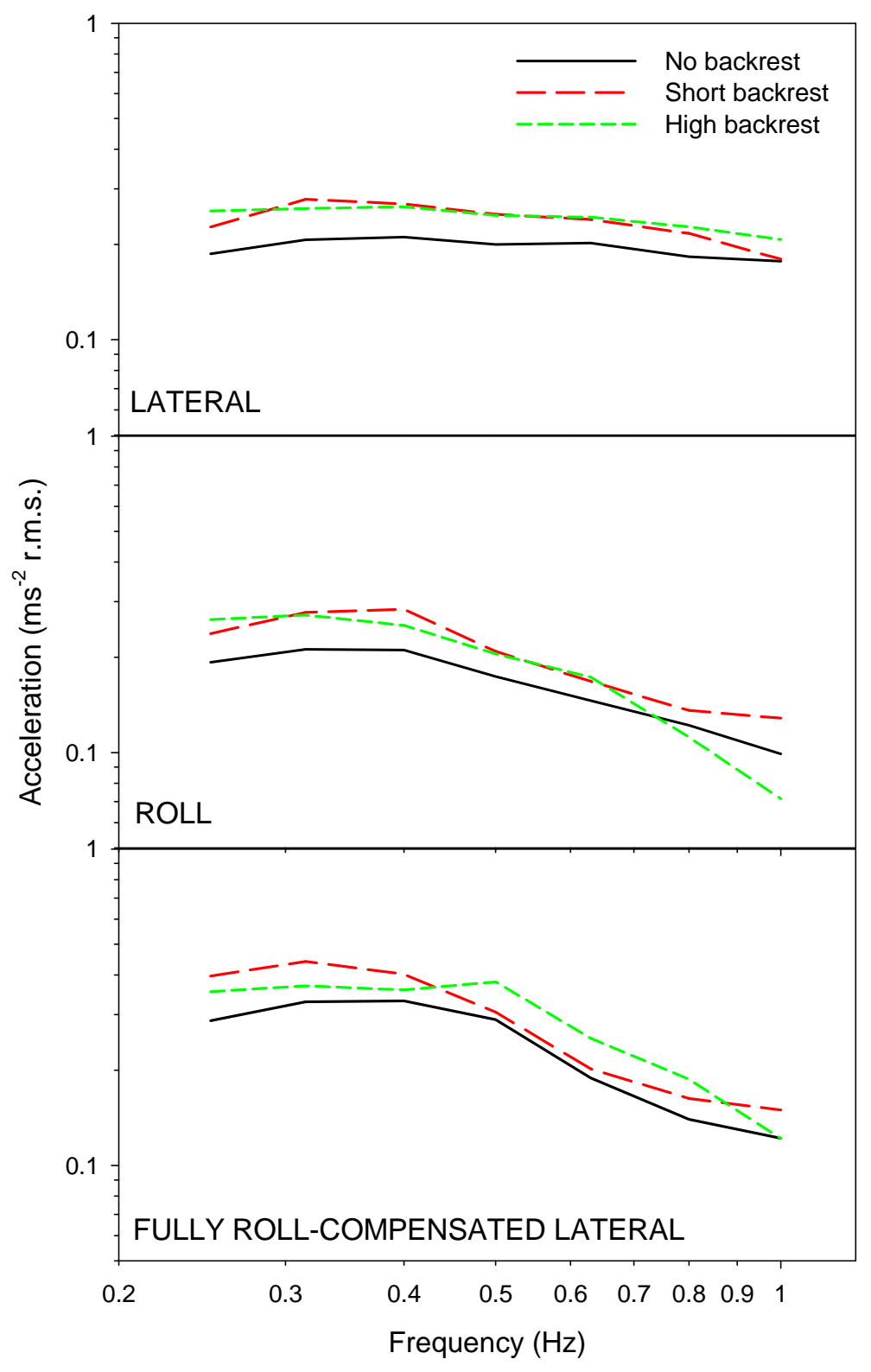

Figure 5 Effect of backrest height on adjusted median equivalent comfort contours for lateral, roll and fully roll-compensated lateral oscillation. Contours represent discomfort equivalent to that arising from lateral oscillation at $0.5 \mathrm{~Hz}, 0.2 \mathrm{~ms}^{-2}$ r.m.s. on a rigid seat without backrest. 


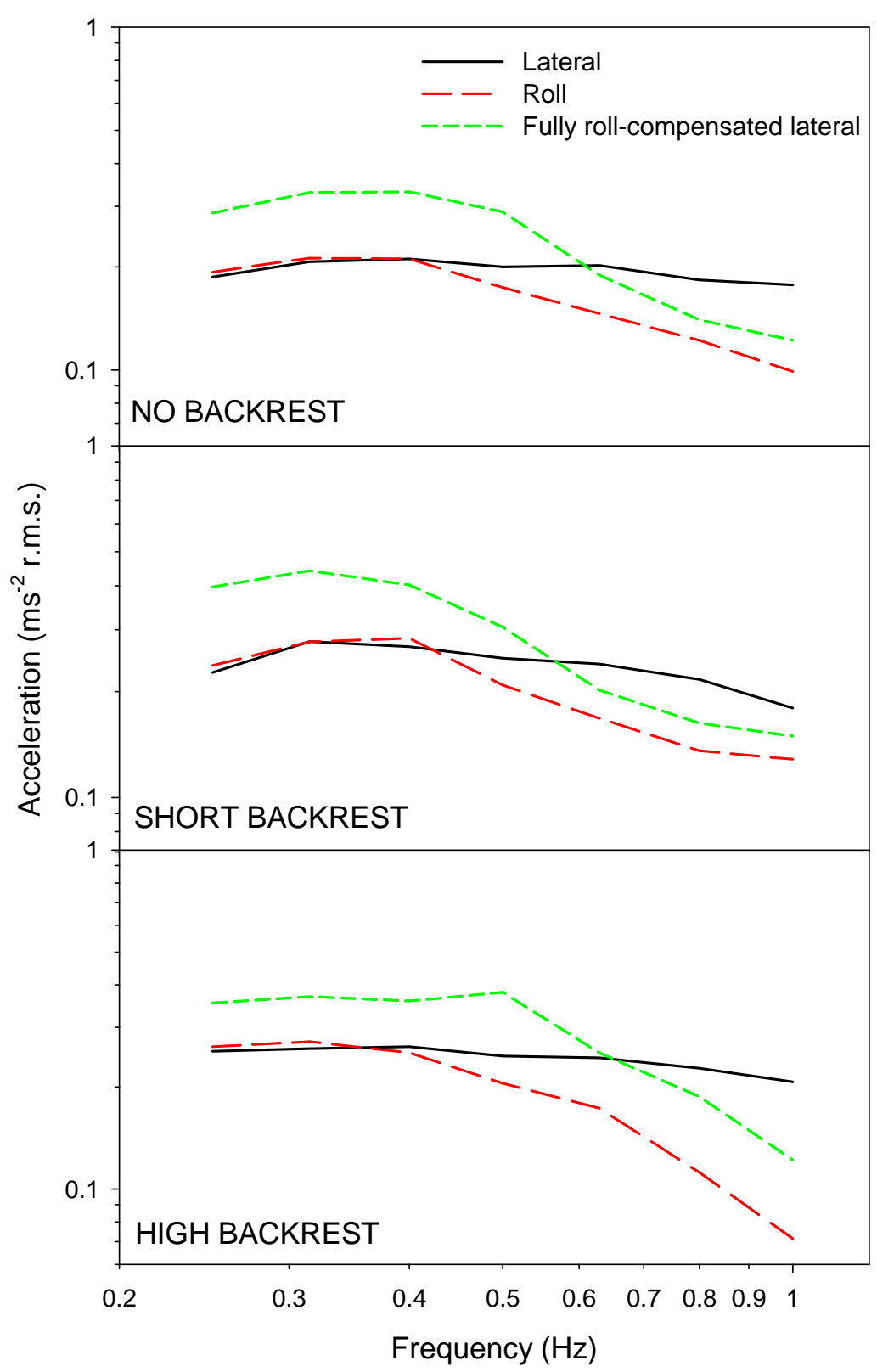

Figure 6 Effect of direction on median equivalent comfort contours for the three seat configurations (no backrest, short backrest, and high backrest). Contours represent discomfort equivalent to that arising from lateral oscillation at $0.5 \mathrm{~Hz} 0.2 \mathrm{~ms}^{-2}$ r.m.s. on a rigid seat without backrest. 


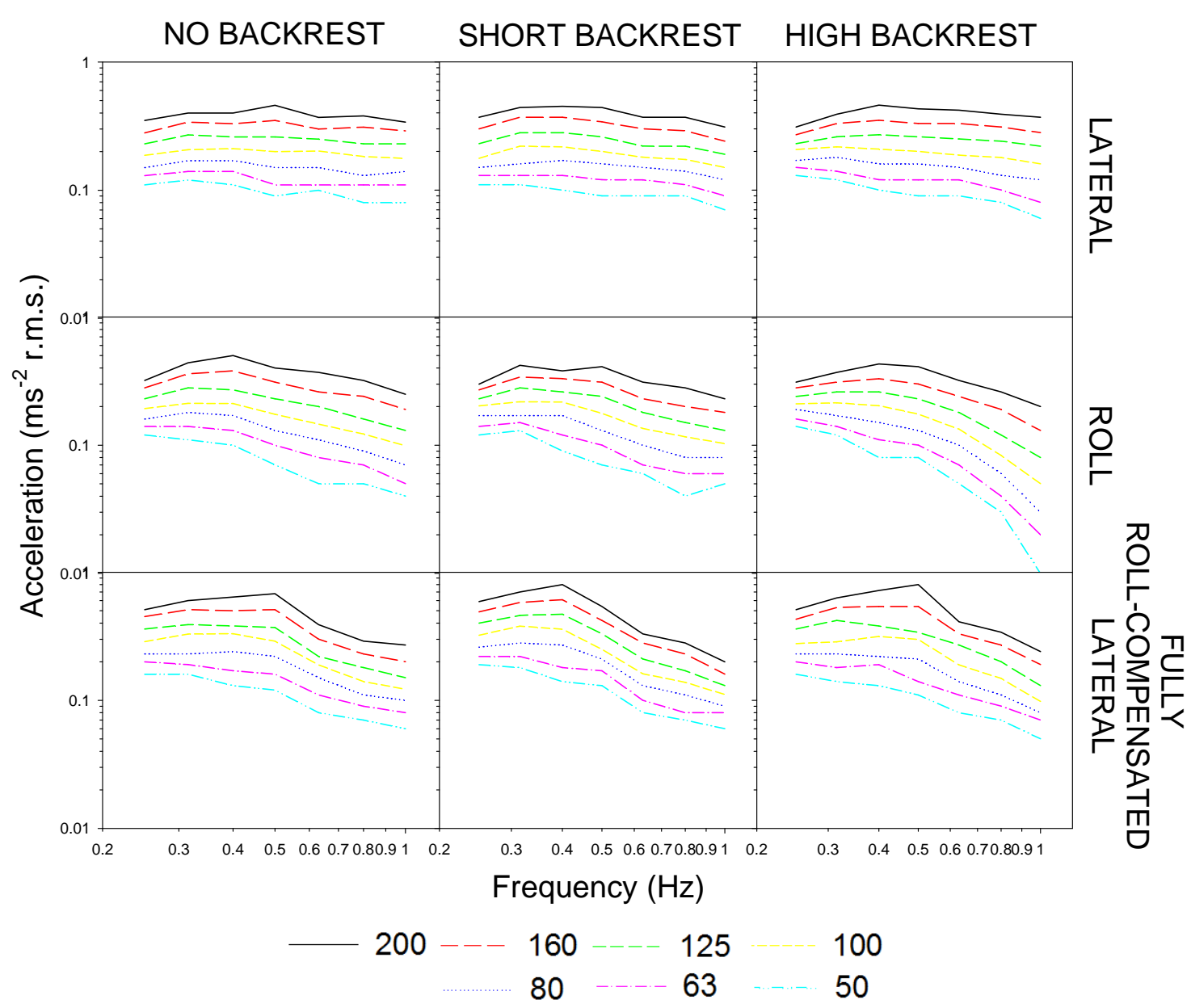

Figure 7 Effect of magnitude of oscillation on equivalent comfort contours for lateral, roll, and fully rollcompensated lateral oscillation when sitting on a rigid seat without a backrest, with a short backrest, and with a high backrest. Contours represent subjective magnitudes of 50, 63, 80, 100, 125, 160 and 200. 


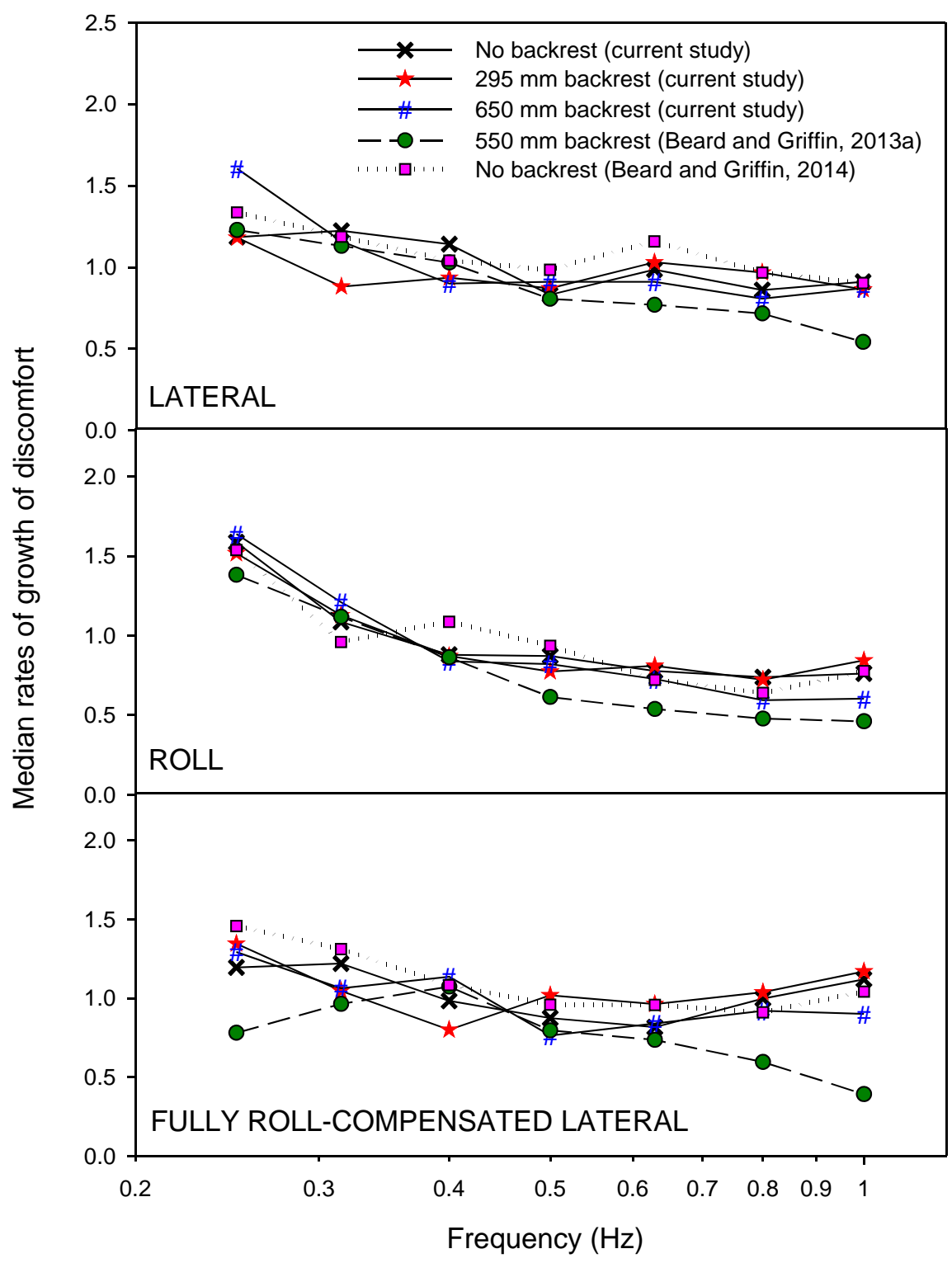

Figure 8 Comparison of median rates of growth of discomfort for lateral, roll, and fully roll-compensated lateral oscillation in the current study and those reported in previous research. 


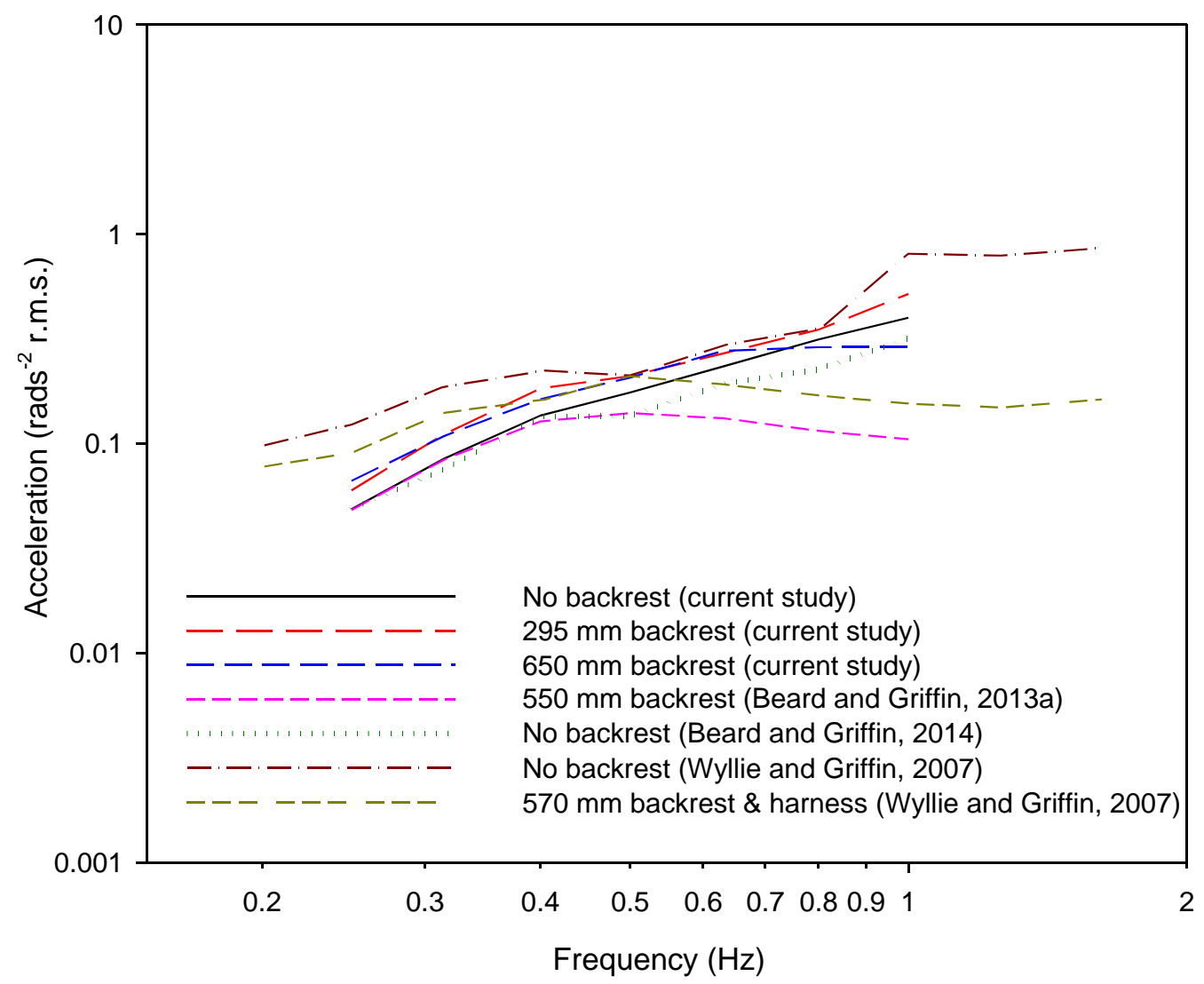

Figure 9 Comparison of equivalent comfort contours for roll oscillation from the current study with those reported in previous research. 

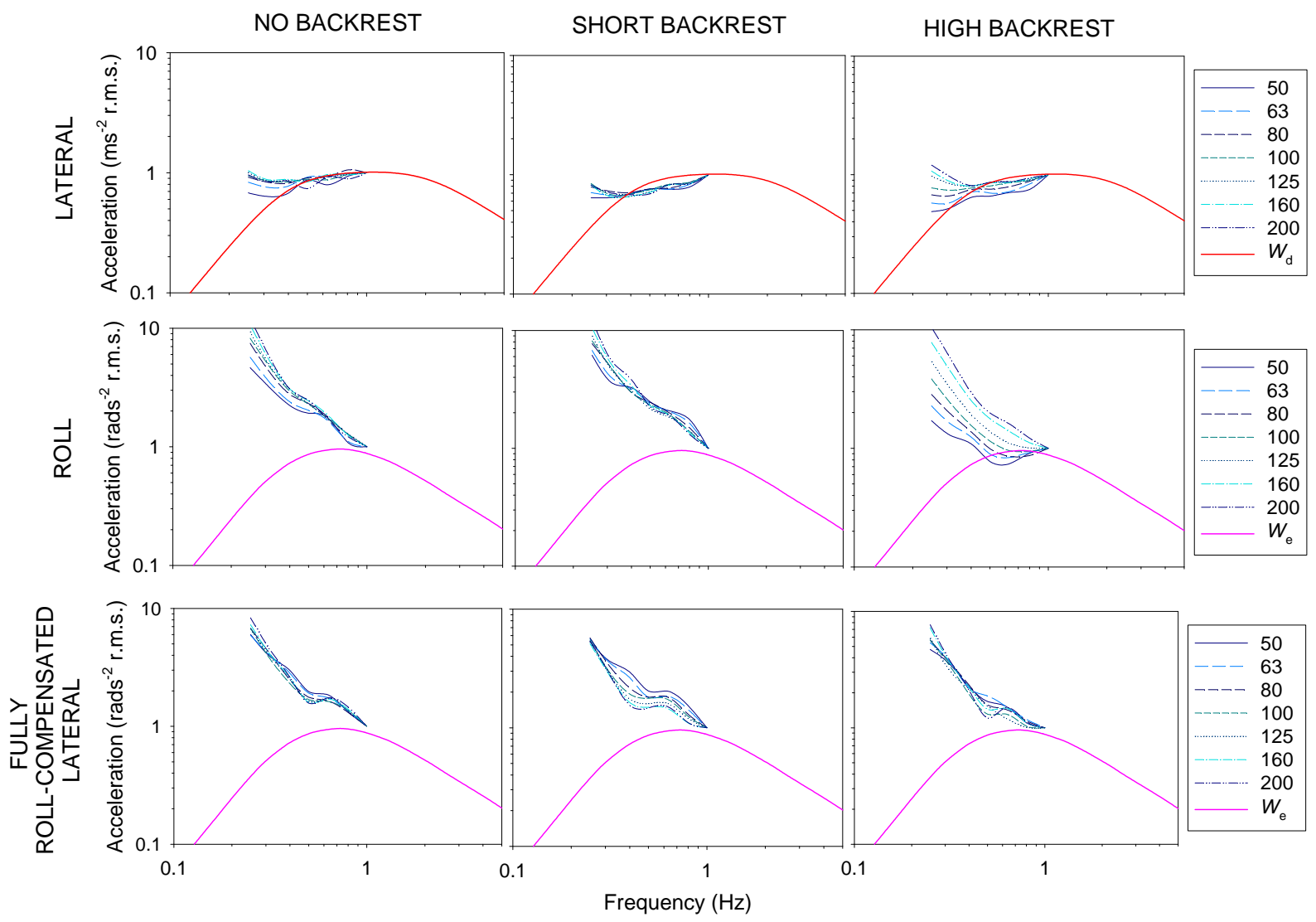

Figure 10 Comparison of current frequency-weightings with inverted median equivalent comfort contours for lateral, roll, and fully roll-compensated lateral oscillation with all backrest conditions. Contours (normalised to unity at $1 \mathrm{~Hz}$ ) represent subjective magnitudes of 50,63, 80, 100, 125, 160 and 200. 